\title{
SIKAP JUJUR MENDASARI TANGGUNG JAWAB
}

\author{
Largus Nadeak*
}

\begin{abstract}
Abstrak
"Tidak ada orang yang tidak membantah jika seorang dalam pusaran kasus", demikian komentar Mahfud MD ketika dirut Asabri membantah bahwa tidak ada korupsi di Asuransi ini. Ungkapan Ibu guru bahasa Inggris saya juga meyakinkan bahwa orang Indonesia terbiasa berdalih. Pilihan berdalih merupakan tindakan tidak jujur dan berentetan dengan ketidaksediaan orang menghadapi dan menerima konsekuensi tindakan, atau tidak mau bertanggung jawab. Tulisan ini menjelaskan bahwa satu sikap yang sangat hakiki yang perlu dilatih dan dibiasakan agar orang bertanggung jawab adalah sikap jujur. Sikap ini tampak dalam pilihan menyatakan kenyataan yang sebenarnya sekaligus membentuk orang berintegritas, yaitu mewujudnyatakan apa yang dikatakan. Sikap ini akan mengoptimalkan kebaikan serta mengakui dan memperbaiki kesalahan. Tanggung jawab personal dijamin oleh keujuran personal yang memancar dari hati nurani yang kuat yang diterangi oleh sinar ilahi dalam iman. Kejujuran personal hendaknya ditopang oleh kolektivitas yang bermutu yang melindungi kebenaran. Kebersamaan jujur dan bertanggung jawab menjadi pelaku dan sekaligus kondisi agar terjadi kedamaian sejati dan kesejahteraan bersama (bonum commune). Kebersamaan beriman harus kuat menghayati pesan Allah, "Orang jujur dipimpin oleh ketulusannya, tetapi penghianat dirusak oleh kecurangannya" (Amsal 11,3).
\end{abstract}

Kata-kata Kunci: Jujur, tanggung jawab, hati nurani, kolektivitas, personal, integritas.

\section{Pendahuluan}

Sikap jujur sebagai pilar kharakter baik menjadi perhatian dewasa ini karena tanggung jawab pribadi dan bersama kurang memuasakan. Tanggung jawab bertumbuh dengan baik kalau pribadi berusaha jujur dan kolektivitas berusaha memelihara kejujuran. Bonum commune nyata secara bertahap kalau kejujuran ditanamakan di kegiatana pendidikan sejak usia dini dan ditopang oleh tindakan jujur yang diwujudyatakan

\footnotetext{
* Largus Nadeak, lisensiat dalam bidang Theologi Moral; lulusan Universitas Lateranensis Academia Alfonsiana, Roma; dosen Theologi Moral pada Fakultas Filsafat Unika St. Thomas, Sumatera Utara.
} 
oleh orang dewasa. Gerakan sikap jujur dan bertanggung jawab membentuk kolektivitas yang berisi damai sejati.

Sikap jujur dan bertanggung jawab merupakan pola hidup yang lahir dari kesadaran internal yang diterangi oleh hati nurani. Orang beriman mengandalkan hati nuraninya yang bermuatan nilai yang bersumber dari ajaran Yesus Kristus. Daya ini tidak dikelabui oleh tuntutan situasi. Allah menganugerahkan daya jujur pada orang beriman, terlebih Dia sendiri berperan aktif menopang kebersamaan masyarakat bertanggung jawab agar terealisris damai sejati.

\section{Dalih Pengaman}

Ketika belajar bahasa Inggris di grup, bersama dengan pelajar berbangsa Jepang, Spanyol, Jerman dan Italia, ibu guru memberi pekerjaan untuk menyusun 7 kalimat "dalih" yang diawali dengan "excuse me" dalam durasi 5 menit. Sebelum 5 menit saya bisa menyelesaikan pekerjaan dengan baik. Saya lihat teman-teman, mereka kesulitan menyusun kalimat bahasa Inggris, dan tidak berhasil merangkai 7 kalimat dalam waktu yang tersedia. Ketika pause Ibu guru mendekat, dan menyapa saya dalam bahasa Indonesia", "Kamu orang Indonesia kan? Tadi kamu berhasil menyusun 7 kalimat dan kalimatmu benar. Walau teman-temanmu tak berhasil menyusun 7 kalimat, bukan berarti kamu lebih mampu berbahasa Inggris. Kamu bisa cepat menyelesaikan pekerjaan karena kamu jelas orang Indonesia yang sejauh saya amati, terbiasa berdalih. Kebiasaan berdalih termasuk salah satu penyebab orang Indonesia secara umum kurang bertanggung jawab atas apa yang sudah dikatakan dan dilakukan." Saya tersentak saat itu, namun ungkapan ibu guru ini membantu saya mengenal dan kemudian mengamati bahwa banyak orang Indonesia yang pintar berdalih dan tampaknya dalih menjadi sesuatu yang normal.

Kenyataan berdalih dan tidak jujur di Indonesia makin terang kalau kita ikuti komentar Mahfud MD atas salah satu kasus di akhir ini yaitu, kasus Asuransi Sosial Angkatan Bersenjata Republik Indonesia

\footnotetext{
${ }^{1}$ Saat itu saya tahu bahwa ibu guru (orang Oxford) tersebut sudah lebih 10 tahun sebagai pebisnis pariwisata dan pelukis di Bali-Indonesia. Sambil libur, dia mengajar bahasa Inggris pada kami "orang asing".
} 
(Asabri). Dia mengatakan, "Tidak ada orang yang tidak membantah jika seorang dalam pusaran kasus." ${ }^{2}$ Komentar ini muncul ketika Dirut Asabri membantah bahwa tidak ada korupsi di Asabri. Biasanya sesudah kecurangan terbukti, beberapa orang mengakui kesalahan, tetapi beberapa lain berusaha tetap berdalih. Bahkan ada orang mengkambinghitamkan orang lain dan merekayasa kejahatan untuk "menjatuhkan" pihak lain. Misalnya Ratna Sarumpaet mengaku dirinya dianiaya, yang mengakibatkan wajahnya bengkak; pada hal nyatanya hal itu adalah akibat dari gagal operasi wajah. $^{3}$

Dalih menjadi pengaman karena kejujuran diduga akan berakibat buruk seperti kena bumerang. ${ }^{4}$ Dalih menjadi jalan keluar untuk menutupi kebutuhan dasar, menutupi rasa takut sesaat, untuk mendatangkan kesenangan dan kuntungan pribadi, tetapi hal itu justeru menipiskan kejujuran, menghilangkan rasa bersalah, menyuburkan ketamakan dan terlebih memandulkan tanggung jawab. ${ }^{5}$

Secara umum di semua daerah (negara) ditemukan ketidakjujuran dengan berdalih, karena dalih merupakan bagian dari mekanisme pertahanan ego, tetapi kadar ketidakjujuran di setiap negara tidak sama. Misalnya, Newsweek 1995 menyatakan bahwa hampir setengah penduduk Amerika kurang memperhatikan standar moral. Sebanyak 93\% orang dewasa berpendapat bahwa orang tua gagal mengajarkan kejujuran, rasa hormat dan tanggung jawab pada anak-anak. Diyakini bahwa pendidikan kejujuran sangat penting karena orang jujur membawa perubahan signifikan demi kesejahteraan pribadi dan bersama. ${ }^{6}$

\section{Sikap Jujur}

Jujur berarti mengatakan kenyataan yang sebenarnya. Kata dan pengungkapan eksternal yang bisa didengar dan dilihat dan diketahui sesuai dengan pemikiran dan pemahaman nyata internal seseorang dan

\footnotetext{
2 Detikcom, https:// finance.detik.com/moneter, (diakses 16 Januari 2020, jam 19.07.)

${ }^{3}$ Detikcom, 07 Mei 2019, jam 13.14.

${ }^{4}$ Jerry White, Kejujuran, Moral dan Hati Nurani (Jakarta: BPK Gunung Mulia 1987), hlm. 99.

5 J. White, Kejujuran, Moral dan Hati Nurani... , hlm. 6, 94-95; bdk. Gregory Hartley Maryann Karinch, How to Spot a Liar, Why People don't Tell the Truth and How You can Catch Them (Petaling Jaya: Advantage Quest Publications, 2012), hlm. 37.

${ }^{6}$ Michele Borba, Membangun Kecerdasan Moral, Tujub Kebajikan Utama agar Anak Bermoral Tinggi (Jakarta: Gramedia Pustaka Utama, 2008), 61.
} 
dengan kenyataan sesungguhnya. ${ }^{7}$ Kejujuran berhubungan dengan integritas yang bermuatan kesesuaian janji dengan perwujudnyataan (membuat nyata apa yang dikatakan/dijanjikan). ${ }^{8}$ Sebaliknya, ketidakjujuran sejajar dengan bohong. "Lying is a speech contrary to what a person has in mind, with the intention to deceive." 9 Bohong berisi pernyataan verbal yang berkontradiksi dengan keyakinan dan pengetahuan benar. Selain dengan bohong, ketidakjujuran terealisir dalam perbuatan menipu, membantah, fitnah, mengkambinghitamkan, dll. Teologi Moral Katolik mendefiniskan bohong, "As locutio contra mentem, a speech contrary to what a person has in mind." 10 Ada ketidaksesuaian pikiran dengan maksud buruk. Perhatian moral tertuju pada tindakan baik dan benar serta tegas menolak ketidakjujuran yang mengelakkan bahkan menghilangkan tanggung jawab.

Ketika membicarakan topik kejujuran, sering muncul pertanyaan, “Apkah kebenaran mutlak harus dinyatakan?” Beberapa ahli mengatakan bahwa berbohong demi melindungi kebaikan yang sangat tinggi bisa diterima. Di awal zaman modern muncul ajaran mental reservation, yang mengatakan bahwa berbohong itu salah tetapi dalam kasus tertentu bisa diterima sebagai jalan keluar sehingga kebenaran dan kebaikan yang lebih besar dilindungi. ${ }^{11}$ Tetapi ajaran ketat mengatakan bahwa "Truthfulness is a high value which must be upheld even if at times it demands scrificies." 12 Kebenaran harus dikatakan maka, "The use of lie in defence of a good which is supposed to be greater than good of truthfulness is nevertheless the use of an evil means for a good end. And this is inadmissible"13 Berbohong adalah satu tindakan jahat dalam dirinya. Tindakan tersebut tetap salah dalam konteks apapapu, dan tak bisa dibenarkan oleh motivasi yang baik dan efek baik yang besar.

\footnotetext{
${ }^{7}$ Karl, H. Peschke, Christian Ethics, Moral Theology in the Light of Vatican II, (vol 2), (Manila: Logos Publications, 2001), hlm. 359.

${ }^{8}$ K. H. Peschke, Christian Ethics..., hlm. 372.

${ }^{9}$ K. H. Peschke, Christian Ethics..., hlm. 361.

${ }^{10}$ K. H. Peschke, Christian Ethics..., hlm. 361.

${ }^{11}$ K. H. Peschke, Christian Ethics..., hlm. 364-365.

${ }^{12}$ K. H. Peschke, Christian Ethics..., hlm. 366.

${ }^{13}$ K. H. Peschke, Christian Ethics..., hlm. 371.
} 
Bohong bisa menjadi dosa berat kalau mengakibatkan bahaya berat pada sesama dan tidak menghormati Allah. ${ }^{14}$

Manusia beriman dipanggil menjadi manusia baru dan berintegritas dengan setia bertindak jujur. Dalam suratnya ke umat di Efesus Paulus bicara tentang manusia baru,

"Kamu telah belajar mengenai Kristus. Karena kamu telah mendengar tentang Dia dan menerima pengajaran di dalam Dia menurut kebenaran yang nyata dalam Yesus, yaitu bahwa kamu berhubung dengan kehidupan kamu yang dahulu, harus meninggalkan manusa lama, yang menemui kebinasaannya oleh nafsunya yang menyesatkan, supaya kamu dibaharui di dalam roh dan pikiranmu, dan mengenakan manusia baru yang telah diciptakan menurut kehendak Allah di dalam kebenaran dan kekudusan yang sesungguhnya. Karena itu buanglah dusa dan berkatalah benar seorang kepada yang lain, karena kita adalah sesama anggota" (Efesus 4, 20-25).

\section{Masyarakat Kolektif yang Damai Palsu}

Sudah lama ada diskusi untuk menentukan apakah hal eksternal atau hal internal yang mempengaruhi sikap manusia. Sejajar dengan itu, apakah hal personal atau lingkungan yang mempengaruhi sikap manusia? Ada yang menonjolkan bahwa hal luar yang utama, ada yang mengatakan bahwa hal internal lebih berperan. Ada yang mengatakan bahwa hal yang lebih kuat dalam pengalaman seseoranglah yang mempengaruhi sikapnya. Guru di tahun 1980-an mengatakan bahwa manusia berpribadi emas diletakkan di mana saja, akan tetap berpribadi emas. Dewasa ini pribadi emas kalau ditempatkan di kebersamaan yang rusak bisa kualitas pribadi luntur bahkan menjadi berpribadi rusak. Kadar otonomi seseorang bisa luntur di kolektivitas yang tidak baik. Pendidikan kejujuran yang diadakan di pendidikan dasar merupakan program pembentukan sikap jujur, tetapi kalau lingkungan yang dihuni anak jujur tersebut, sungguh koruptif, bisa saja kejujurannya luntur. Apa yang dilakukan orang dewasa lebih berpengaruh pada anak, dari pada apa yang dikatakan. ${ }^{15}$

\footnotetext{
${ }^{14}$ K. H. Peschke, Christian Ethics..., hlm. 367.

${ }^{15}$ M. Borba, Membangun Kecerdasan Moral..., hlm.70.
} 
Kolektivitas bisa menjadi pelaku kegiatan, dan juga menjadi lahan hidup personal untuk tumbuh bersama dalam kebenaran. Kolektivitas menjadi kondisi subur untuk pribadi agar bertanggung jawab. Namun kolektivitas yang berkualitas rendah pengandal kolusi dan nepotis me bisa menjadi lahan penghilang tanggung jawab pribadi dan bersama. Dan kolektivitas demikian bisa menjadi sejenis perangkap sehingga pribadi sulit keluar untuk bertanggung jawab. ${ }^{16}$

Kolektivitas berkuliatas rendah yang kolusif dengan mudah kelihatan karena sering terjadi di sekitar kita. Misalnya, ada tabrakan kendaraan di jalan. Ada saja pihak yang tidak jujur mangakui kesalahan. Lebih sering pihak membenarkan diri dan mempersalahkan orang lain, serta mengandalkan kenalan yang berposisi tinggi (kolusi dan nepotisme). Masalah makin rumit karena kenalan yang berposisi tinggi tersebut yang seharusnya menuntun orang untuk bertanggung jawab justeru dengan bangga menunjukkan "kebaikan palsu" dengan membenarkan yang salah. Permasalahan diatasi dengan jalan pintas salah. Dalam kondisi kolektivitas kolusif begini orang tidak belajar bertanggung jawab sehingga bertumbuh kedamaian palsu.

Dalam kebersamaan dan lingkungan begini sulit berkembang kejujuran personal. ${ }^{17}$ Orang sadar tidak ingin berbohong dan menipu orang tetapi senang melakukannya di kala ada keuntungan pribadi yang dikejar, atau kerugian pribadi yang harus ditutupi. Di konsidi seperti ini, orang protes kalau dia korban korupsi dan dirugikan oleh oleh orang lain dalam kondisi kolusif, tetapi dia diam kalau dia bisa korupsi dan diuntungkan.

\section{Tanggung Jawab Personal}

Pribadi yang jujur adalah pribadi yang bersedia menghadapi dan bertanggung jawab atas kenyataan yang dihadapi yang diakibatkan oleh pilihan maupun tindakannya, baik yang mendatangkan keuntungan dan juga yang sudah diketahui dan yang belum diketahui akan mendatangkan kerugian. Kadang tanggung jawab tidak bisa diemban karena

${ }^{16}$ G. Hartley - M. Karinch, How to Spot a Liar..., hlm. 25.

17 Josef Fuchs, Personal Responsibility and Christian Morality (Washington, Georgetown University Press 198), hlm. 158. 
keterbatasan, namun manusia mampu berkembang dan mengatasi keterbatasan nyata karena bereksistensi beriman dalam Kristus Penebus dan sumber dari "liberation of the whole man". ${ }^{18}$

Jesus melarang mengucapkan saksi dusta dan hal ini salah satu dari dekalog (Mk 10:19). Dia juga mendesak para murid agar menghayati kebenaran absolut. "Their "Yes" and "No" must be so reliable that no further confirmation of their words, such as by oath, be needed" (Mt 5, $37)^{19}$ Orang beriman harus belajar jujur pada diri. Dengan demikian ada pengakuan akan keterbatasan, ada kesediaan untuk berubah ketika menemukan diri bersalah. ${ }^{20}$

Orang jujur mengikuti seruan hati nurani (kesadaran bahwa demi pertimbangan apa pun orang tidak dibenarkan bertindak melawan apa yang disadari sebagai benar), yaitu bahwa manusia dalam segala sikap dan tindakan-tanduk harus dimengerti dalam realitas ilahi. ${ }^{21}$

\section{Masyarakat Bersaudara, Damai, dan Bertanggung Jawab}

Kebersamaan bisa berisi ketidakjujuran dan damai palsu, tetapi juga berisi rahmat. Masyarakat bersaudara, damai dan bertanggung jawab terjadi kalau setiap pribadi berusaha jujur dan didukung oleh sistem yang baik. Ikatan tanggung jawab yang langsung direalisasikan terhadap sesama dalam hidup nyata adalah dasar hidup etis. Ikatan tanggung jawab demikian tidak lagi diwajibkan oleh aturan tetapi menjadikan pribadi dan kebersamaan teratur dan terdorong menunaikan tata bersama ${ }^{22}$

Hidup bersama yang baik terjadi kalau kebenaran dihidupi. ${ }^{23}$ What is radically rigt is not to be sought in an abstract ideal, nor in a goal that seem obligarory but turns out to be unattainable, but in the best possible developement of rality as it is encountered. ${ }^{24}$ Kebersamaan harus saling menghormati karena sesama adalah manusi "luhur", terhadapnya ada kaitan tanggung jawab. Yang Tak Terhingga muncul di dalam

\footnotetext{
${ }^{18}$ J. Fuchs, Personal Responsibility..., hlm. 159, 167.

${ }_{19}$ K. H. Peschke, Christian Ethics..., hlm.362.

${ }^{20}$ K. H. Peschke, Christian Ethics..., hlm. 356-357.

${ }^{21}$ F. Magnis-Suseno, 12 Tokoh Etika Abad ke-20 (Yogyakarta: Kanisius, 2000), hlm. 105.

${ }^{22}$ F. Magnis-Suseno, 12 Tokoh Etika Abad ke-20..., hlm. 107.

${ }^{23}$ K. H. Peschke, Christian Ethics..., hlm. 359.

${ }^{24}$ J. Fuchs, Personal Responsibility..., hlm. 168.
} 
"keluhuran" sesama. Segenap sesama tanpa kecuali, menjadi tanggung jawab kita yang mengikat kita untuk menghormati dan menyelamatkannya, karena dalam "keluhuran" "muka" segenap sesama tanpa kecuali "nampak" "kemuliaan" "Yang-Tak-Terhingga". ${ }^{25}$

Kristus Penyata Allah Yang Tak Terhingga adalah kebenaran absolut. Dia mewartakan misteri Allah secara bertahap (Mt 7,6). Kristus menganjarkan bahwa cinta menuntut kebenaran dan kebenaran menumbuhkan cinta sejati, yang bertentangan dengan kebersamaan kolusif yang damai palsu. $^{26}$

Persaudaraan sekarang dan masa depan mengakui pluralitas multi kultur sebagai kondisi untuk menguatkan jaringan komunikasi interkultur. 27 Manusia berinterrelasi dengan orang dan dengan pengalaman kontekstual, tetapi yang utama "He realizes his own self in his totally as a free, self-determining and interpersonal being." ${ }^{28}$ Itu berarti, keberlainan setiap orang tidak dapat dicairkan dengan interpretasi apapun. ${ }^{29}$ Orang beriman dalam menerapkan kebenaran tentu memperhatikan kebijakan yang menjembatani perbedaan yang memuliakan Allah, bukan sebaliknya membuat kebersamaan menjadi terpecah dan rusak. ${ }^{30}$

Negara New Zealand dan Finlandia mendapat sorotan pujian karena berada di posisi tertinggi sebagai negara bermasyarakat jujur. Masyarakat 2 negara ini hidup sejahtera dan secara personal sadar mengikuti aturan yang ada. Kalau terjadi pelanggaran aturan, penegak hukum menyelesaikannya secara adil, sehingga masyarakat berusaha bertanggung jawab. Penyelesaian masalah tidak dengan mengandalkan hubungan kolusif. Kebersamaan ikut melindungi kebaikan personal dan setiap orang menguatkan kebersamaan karena sadar demi kesejahteraan bersama (bonum commune).

\footnotetext{
${ }^{25}$ F. Magnis-Suseno, 12 Tokoh Etika Abad ke-20..., hlm. 108-109.

${ }^{26}$ K. H. Peschke, Christian Ethics..., hlm. 360.

${ }^{27}$ J. Fuchs, Personal Responsibility..., hlm. 99-100.

28 J. Fuchs, Personal Responsibility..., hlm. 216.

${ }^{29}$ F. Magnis-Suseno, 12 Tokoh Etika Abad ke-20..., hlm. 107.

${ }^{30}$ K. H. Peschke, Christian Ethics..., hlm. 360.
} 


\section{Hati Nurani Berfungsi Baik}

"It is morally correct that man realize his human existence by

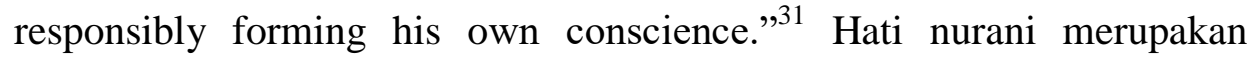
sanggar suci tempat manusia berkomunikasi dengna Allah. ${ }^{32}$ Hati Nurani adalah kemampuan kognitif yang dianugerahakan Allah pada manusia, yang memampukannya untuk membedakan yang baik dari yang buruk, serta mendesak manusia untuk melakukan yang baik. ${ }^{33}$

Agar hati nurani berfungsi baik, orang beriman wajib mencari kebenaran secara khusus kebenaran iman. Manusia wajib "seraya mengindahkan tata nilai moral serta kepentingan masyarakat, dapat dengan leluasa menyelidiki kebenaran dan menyatakan serta menyiarkan pendapatnya..., akhirnya diisyaratkan pula, bahwa manusia mendapat informasi tentang peritiwa-peristiwa umum dengan kebenaran." ${ }^{34}$ Hati nurani yang tajam mendesak (imperatif kategoris) orang untuk bertanggung jawab. Tindakan jujur (kata dan perbuatan sejajar) dan bertanggung jawab menjadi tanda orang beriman pada Kristus. ${ }^{35}$

Ada 4 hal penting diperhatikan agar hati nurani, kebebasan, penentuan diri bisa bermakna: "1) an understanding of the nature, meaning and destiny of man; 2) an experience of the imperative character both of the inner demand to realize the self and also of the type of behavior by which such self-realization can be correctly known and experienced; 3) a comprehension of the importance which self-realization and self-alienation have for the genuine and final destiny of man; 4) a spiritually attractie impulse to achieve all of these goods. ${ }^{36}$

Berani dan bertahan jujur akan menumbuhkan tanggung jawab. "Do good, follow Christ, be just and chaste, protect life as much as possible! Precisely because they are strongly formal in character and do

\footnotetext{
${ }^{31}$ J. Fuchs, Personal Responsibility..., hlm. 100.

32 Dokumentasi dan Penerangan KWI, "Gaudium et Spes”, dalam Dokumen Konsili Vatikan II, (Obor, Jakarta 1993), no. 16.

${ }^{33}$ Largus Nadeak, Topik-topik Teologi Moral Fundamental, Memaham Tindakan Manusiawi dengan Rasio dan Iman (Medan: Bina Media Perintis, 2015), hlm. 85.

${ }^{34}$ Dokumentasi dan Penerangan KWI, “Gaudium...", no. 59.

${ }^{35}$ K. H. Peschke, Christian Ethics..., , hlm. 357.

${ }^{36}$ J. Fuchs, Personal Responsibility..., hlm. 218
} 
not as yet deal with concrete situasions...." 37 Daya ini tidak dikelabui oleh tuntutan situasi. Allah menganugerahkan daya tahan dan daya jujur pada orang beriman, terlebih Dia berperan aktif menopang kebersamaan masyarakat yang damai sejati. ${ }^{38}$

\section{Penutup}

Kolektivitas yang ditopang oleh relasi keluarga, suku, agama cukup kental di Nusantara ini. Kondisi nyata ini merupakan satu modal berharga untuk membangun persaudaraan damai sejati kalau sikap jujur dan siap bertanggung jawab makin kental juga. Ungkapan yang subur di kolektivitas palsu, "Jujur hancur, tidak jujur makmur" seharusnya dihapus dan diganti dengan, "Jujur makmur, tidak jujur hancur", agar sikap bertanggung jawab makin subur. Kebersamaan beriman harus kuat menghayati pesan ilahi, "Orang jujur dipimpin oleh ketulusannya, tetapi penghianat dirusak oleh kecurangannya” (Amsal 11, 3).

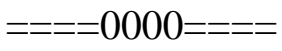

\footnotetext{
37 J. Fuchs, Personal Responsibility..., hlm. 224
}

38 J. Fuchs, Personal Responsibility..., hlm. 98. 


\section{DAFTAR PUSTAKA}

Borba, Michele. Membangun Kecerdasan Moral, Tujuh Kebajikan Utama agar Anak Bermoral Tinggi. Jakarta: Gramedia Pustaka Utama, 2008.

Dokumentasi dan Penerangan KWI. "Gaudium et Spes", dalam Dokumen Konsili Vatikan II. Obor: Jakarta,1993.

Fuchs, Josef, Personal Responsibility and Christian Morality. Washington: Georgetown University Press, 1983.

Hartley, Gregory - Karinch, Maryann. How to Spot a Liar, Why People don't Tell the Truth and How You can Catch Them. Petaling Jaya: Advantage Quest Publications, 2012.

Magnis-Suseno, Franz. 12 Tokoh Etika Abad ke-20. Yogyakarta: Kanisius, 2000.

Nadeak, Largus. Topik-topik Teologi Moral Fundamental, Memaham Tindakan Manusiawi dengan Rasio dan Iman. Medan: Binamedia Perintis, 2015.

Peschke, Karl, H. Christian Ethics, Moral Theology in the Light of Vatican II, (vol 2). Manila: Logos Publications, 2001.

White, Jerry, Kejujuran, Moral dan Hati Nurani. Jakarta: BPK Gunung Mulia, 1987. 